\title{
Estimation of Groundwater Evapotranspiration Using Diurnal Groundwater Level Fluctuations under Three Vegetation Covers at the Hinterland of the Badain Jaran Desert
}

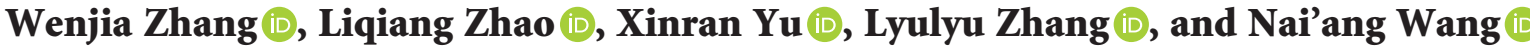 \\ Center for Glacier and Desert Research, College of Earth and Environmental Sciences, Lanzhou University, Chengguan, Lanzhou, \\ Gansu 73000, China \\ Correspondence should be addressed to Nai'ang Wang; wangna1962lzu@163.com
}

Received 1 August 2019; Revised 2 January 2020; Accepted 28 January 2020; Published 9 March 2020

Academic Editor: Panuganti C. S. Devara

Copyright $(92020$ Wenjia Zhang et al. This is an open access article distributed under the Creative Commons Attribution License, which permits unrestricted use, distribution, and reproduction in any medium, provided the original work is properly cited.

Accurate estimation of groundwater evapotranspiration $\left(\mathrm{ET}_{\mathrm{G}}\right)$ is the key for regional water budget balance and ecosystem restoration research in hyper-arid regions. Methods that use diurnal groundwater level (GWL) fluctuations have been applied to various ecosystems, especially in arid or semi-arid environments. In this study, groundwater monitoring devices were deployed in ten lake basins at the hinterland of the Badain Jaran Desert, and the White method was used to estimate the $\mathrm{ET}_{\mathrm{G}}$ of these sites under three main vegetation covers. The results showed that regular diurnal fluctuations in GWL occurred only at sites with vegetation coverage and that vegetation types and their growth status were the direct causes of this phenomenon. On a seasonal scale, the amplitudes of diurnal GWL fluctuations are related to vegetation phenology, and air temperature is an important factor controlling phenological amplitude differences. The estimation results using the White method revealed that the $\mathrm{ET}_{\mathrm{G}}$ rates varied among the observation sites with different vegetation types, and the months with the highest $\mathrm{ET}_{\mathrm{G}}$ rates were also different among the sites. Overall, $\mathrm{ET}_{\mathrm{G}}$ was $600 \sim 900 \mathrm{~mm}$ at observation sites with Phragmites australis during a growing season (roughly early May to late October), $600 \sim 650 \mathrm{~mm}$ in areas with Achnatherum splendens, and 500 650 $\mathrm{mm}$ in areas with Nitraria tangutorum and

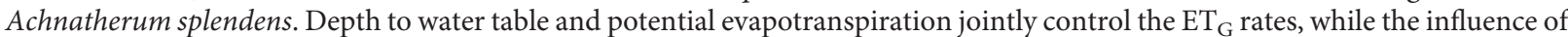
these two factors varied, depending on the specific vegetation conditions of each site. This study elucidated the relationship between diurnal GWL fluctuations and vegetation in desert groundwater-recharged lake basins and expanded the application of the White method, providing a new basis for the calculation and simulation of regional water balance.

\section{Introduction}

In arid and semi-arid regions where precipitation is scarce, most vegetation depends on groundwater for survival. Estimation of groundwater evapotranspiration $\left(\mathrm{ET}_{\mathrm{G}}\right)$ is an important component of regional water-balance studies. Vegetation growth is usually closely related to groundwater via complex feedback mechanisms [1], and the spatiotemporal variations of vegetation are largely determined by groundwater availability $[2,3]$. In the previous research, the depth to water table (DTWT) determined the spatial distribution of riverside vegetation [4], and evapotranspiration was highly correlated with the spatial distribution of vegetation [5] in arid and semi-arid regions. Thus, in hyper-arid desert ecosystems, it is critical to fully understand the interactions between groundwater and vegetation and accurately estimate the amount of groundwater consumed by vegetation for the management of regional groundwater resources.

Conventional $\mathrm{ET}_{\mathrm{G}}$ calculating methods (e.g., the eddy covariance method, lysimeter method, Penman model, and remote-sensing inversion model) either cannot directly determine $\mathrm{ET}_{\mathrm{G}}$ or demand high research cost to cover in large-scale study regions. Moreover, some observational methods may be too complex to carry out under harsh field conditions. In areas with a shallow DTWT, diurnal groundwater level (GWL) fluctuations can usually be observed, which is attributed to regular water consumption by 
phreatophytes when other factors are negligible $[6,7] . \mathrm{ET}_{\mathrm{G}}$ can be estimated from diurnal GWL fluctuations, which was first proposed by White [6]. This estimation approach is thus referred to as the White method and has since been frequently used for evapotranspiration calculation. Compared with other methods, $\mathrm{ET}_{\mathrm{G}}$ calculation methods such as the highly complex and costly eddy covariance method, as well as the assumption of land surface homogeneity [8], the White method has the advantages of being cost-effective, relatively simple, and applicable to long-term continuous observations [9-11]. These characteristics highlight the practicality of the White method for $\mathrm{ET}_{\mathrm{G}}$ estimation, and thus it has been continually developed and revised since its proposal [12-15]. Currently, these methods have been applied to various ecosystems, such as wetland environments $[16,17]$ and riverside oases in arid and semi-arid regions $[11,18,19]$. In the hyper-arid hinterland of the Badain Jaran Desert, vegetation growing in groundwater-recharged lake basins depends on groundwater for survival. Thus, the White method could be used to estimate $\mathrm{ET}_{\mathrm{G}}$ in this hyper-arid desert lake ecosystem.

Accurate $\mathrm{ET}_{\mathrm{G}}$ estimation using the White method is based on an understanding of groundwater dynamics and its relationship with vegetation. The information extracted from diurnal GWL fluctuations is also used to study the interaction between groundwater and vegetation $[10,20]$. For example, Engel et al. [21] observed diurnal GWL fluctuations in wooded areas during the growing season, but the neighboring grassland did not exhibit this phenomenon during the period. De Castro Ochoa and Reinoso [22] found that elevated temperatures caused an increase in the vegetation transpiration rate. When rising temperatures reach a critical point, transpiration ceased due to leaf stomatal closure, and these changes were reflected in daily GWL fluctuations. Another study revealed that vegetation types, meteorological conditions, and soil properties jointly determine the magnitude of diurnal GWL fluctuations [7]. Overall, the existing research highlights the close relationship between phreatophytes and their surrounding environment, but the actual field observation studies remain limited $[23,24]$. Therefore, the dynamic characteristics of groundwater and its relationship with external conditions require further study. Moreover, the analysis of major factors affecting the $\mathrm{ET}_{\mathrm{G}}$ rate would help elucidate the complex relationship between groundwater and vegetation.

The formation mechanism of the 110 permanent lakes at the hinterland of the Badain Jaran Desert in northwestern China is controversial, and the uncertainty of water consumption in the lake basin is the primary cause of this dispute. The lake basins in the desert hinterland have a considerable area with shallow groundwater, where vegetation flourishes during approximately half of the year. Therefore, $\mathrm{ET}_{\mathrm{G}}$ cannot be neglected and is a critical component of the water balance calculation in the region. However, the desert hinterland presents an adverse environment for field workers, hindering the long-term research. Most monitoring methods can only be performed at a single site for in situ observations or in a small-scale area, which hinders the effective monitoring of the vegetation-driven spatiotemporal variations in water requirements. Furthermore, water resource management usually requires the prediction of future water demands based on the current ecosystem water demands under the intervention of human activities. Therefore, the daily dynamic characteristics of GWL and the relationship between vegetation and groundwater dynamics must be clarified first, after which a simple and practical estimation approach to calculate the water requirements of oasis vegetation in the desert hinterland can be developed. Such an approach would support the rational usage of water resources and provide scientific evidence for the aforementioned unsolved problems. Therefore, this study sought to monitor the shallow groundwater in the desert hinterland-recharged lake basins of the hyper-arid Badain Jaran Desert to estimate the $\mathrm{ET}_{\mathrm{G}}$.

\section{Materials and Methods}

2.1. Study Site. The Badain Jaran Desert $\left(39^{\circ} 04^{\prime} 15^{\prime \prime} \sim 42^{\circ} 12^{\prime} 23^{\prime \prime} \mathrm{N}\right.$, $99^{\circ} 23^{\prime} 18^{\prime \prime} \sim 104^{\circ} 34^{\prime} 02^{\prime \prime} \mathrm{E}$ ) is located in the Alashan Plateau, western Mongolian Autonomous Region, China. It is roughly to the south of the ancient Juyan and Guaizi Lakes, north of the Heli and Beida Mountains, west of the Yabrai and Zong Nai Mountains, and east of the Gurinai Plain, with an area of approximately $52,200 \mathrm{~km}^{2}$ [25]. The study area lies within the northwestern marginal region of the East Asian summer monsoon with a continental climate. The summer and winter mean daily temperatures are $25.3^{\circ} \mathrm{C}$ and $-9.1^{\circ} \mathrm{C}$, respectively [26]. The mean annual precipitation is $\sim 100 \mathrm{~mm}$, which is mainly concentrated in May to September and exhibits large interannual variability [27]. The mega-dunes and lakes in the desert are interdependent, and there are 110 perennial groundwater-recharged lakes, most with an area $<1 \mathrm{~km}^{2}$ [28]. The groundwater recharge process mainly occurs through cretaceous and tertiary sandstone, and the space that allows for shallow groundwater circulation is dominated by the quaternary gravel, fine sand, and fine silty sand [29].

The Badain Jaran Desert has closed freshwater lakes, saltwater lakes, and salt/brine lakes classified by the total dissolved solids content in the water. The vegetation landscape of the lake basin is characterized by ring zone distributions around the water [30]. Waterfront regions are swampy meadows, with a groundwater depth $<0.5 \mathrm{~m}$, and short and dense vegetation including species such as Triglochin maritima and Glaux maritima. The second belt around the water is mostly saline meadow, with a groundwater depth of $\sim 1 \mathrm{~m}$ and vegetation featuring Achnatherum splendens, Phragmites australis, and Glycyrrhiza uralensis. The outer belt has a groundwater depth of $\sim 2 \mathrm{~m}$ and vegetation cover comprising Nitraria tangutorum and Artemisia salsoloides. The outermost edge of vegetation is distributed among fixed and semifixed sand dunes, connected to quicksand. The lake ecosystem in the Badain Jaran Desert, with minimal human activities, is ideal for the study of ecohydrological processes in hyper-arid areas. The research team has established ten GWL monitoring sites in the desert lake basins since 2010 (Figure 1); the present study represents the first analysis of the data from these sites. 


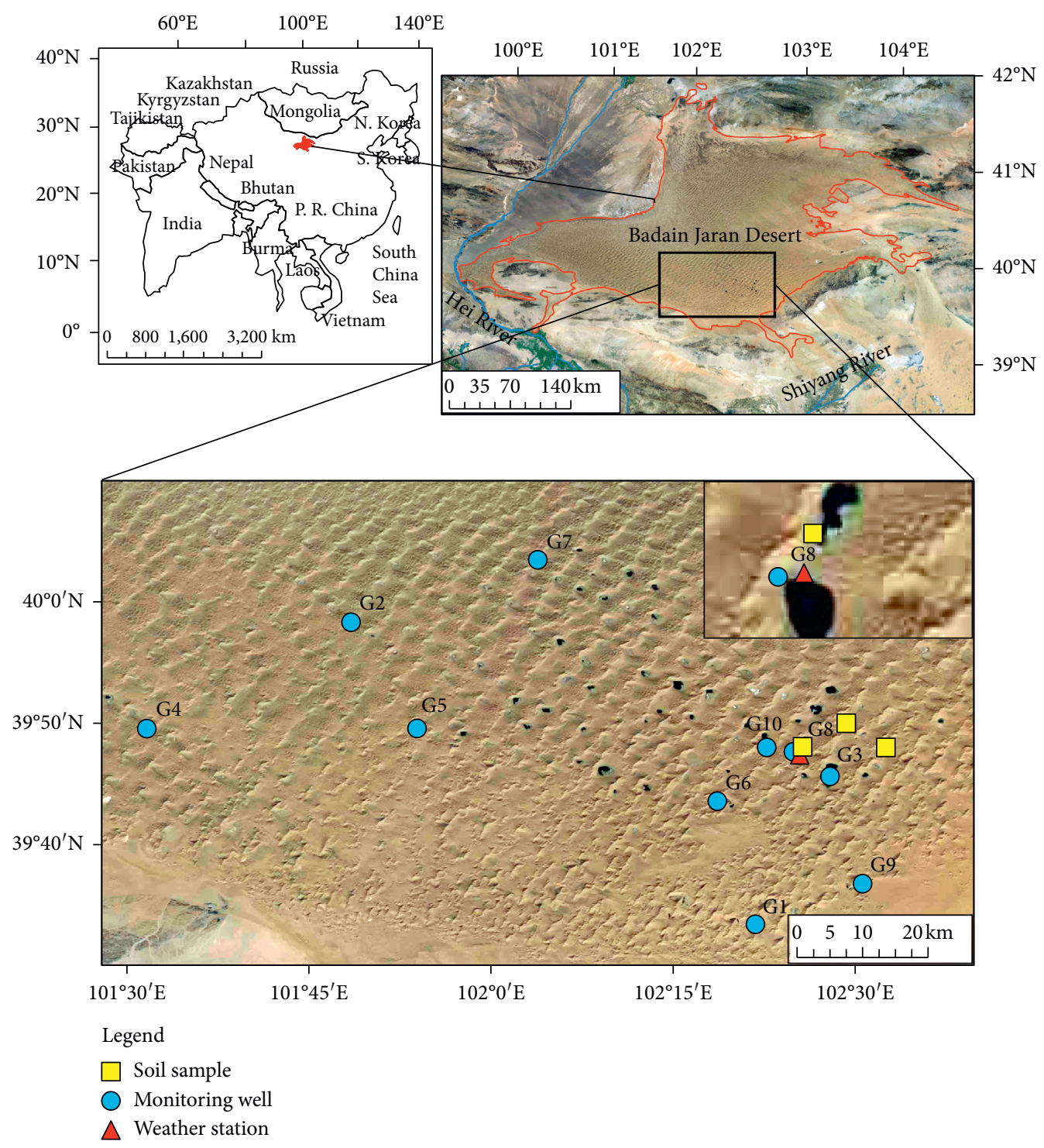

Figure 1: Location of the study area and observation sites.

2.2. Observation and Data Processing of GWL and Meteorological Parameters. Ten groundwater observation wells were established in different lake basins with shallow groundwater, which were constructed with PVC screens with a diameter of $8 \mathrm{~cm}$. Hourly GWL was measured with a pressure transducer (Solinst 3001; Solinst Canada Ltd., Georgetown, ON, Canada), which had a measurement accuracy of $0.1 \mathrm{~cm}$, clock accuracy of $\pm 1 \mathrm{~min} /$ year, and work temperature range of $-10^{\circ} \mathrm{C}$ to $40^{\circ} \mathrm{C}$. The DTWT was $0 \sim 2 \mathrm{~m}$ at the observation wells, and the transducers were fixed at $\sim 30 \mathrm{~cm}$ below the water table. The transducer measured both the total pressure of the water column above the probe and the atmospheric pressure, which was revised using a Barologger barometer (Solinst). The daily changes in GWL in the observation wells were calculated during the growing season, which was defined as the difference between the maximum and minimum values within a day (amplitude in $\mathrm{cm}$ ). Because missing data could affect the calculation, data were only considered if more than $90 \%$ of the normal daily total amount of hourly data were collected; otherwise, the amplitude for that day was excluded from the analysis. Before groundwater series were applied to the White method, a median smoothing filter in MATLAB was applied to eliminate noise.

To obtain meteorological parameters, a weather station (MAWS-301; Vaisala, Vantaa, Finland) was established on the flat ground between Sumujilin South and North lakes at the hinterland of the Badain Jaran Desert. A QMH102 sensor (Vaisala) was used to observe temperature $\left({ }^{\circ} \mathrm{C}\right)$ and relative humidity $(\mathrm{RH}, \%)$ with an observation interval of $10 \mathrm{~s}$ and an output interval of $10 \mathrm{~min}$. An NR01 net radiation sensor (Hukseflux Thermal Sensors, Delft, the Netherlands) was used to observe radiation $(\mathrm{Rg}, \mathrm{W} / \mathrm{m})$, with output every $30 \mathrm{~min}$. Precipitation $(\mathrm{mm})$ was monitored with a $\mathrm{HOBO}$ RG3-M (Onset Computer Corp., Bourne, MA, USA) tilting rain gauge, recorded in rain events with an accuracy of $0.2 \mathrm{~mm}$ /gauge. Based on the observed data, the daily mean temperature, daily mean $\mathrm{RH}$, daily $\mathrm{Rg}$, and daily 
precipitation were used for subsequent analysis. $\mathrm{Rg}$ and precipitation were the total amounts in a day, and the temperature was the mean of values at $03: 00,09: 00,15: 00$, and $21: 00$ (China Standard Time). Moreover, daily maximum and minimum temperature, $\mathrm{RH}, \mathrm{Rg}$, and wind speed (WS, m/s) were used to calculate potential evapotranspiration (PET) based on the Penman-Monteith (FAO56) method [31]. The data involved in this study were all observation records for the year 2014 .

\subsection{Estimation of $E T_{G}$ from the Diurnal Fluctuations in} $G W L$. In the revised White method, Loheide improved the calculation accuracy in areas with shallow DTWT and ET $_{\mathrm{G}}$ can be estimated on an hourly basis [32]. Thus, this improved method will be henceforth referred to as the Loheide method, which was applied to estimate the $\mathrm{ET}_{\mathrm{G}}$ of eight observation sites under various vegetation conditions. Several assumptions were analyzed and discussed to explain the suitability and reduce the uncertainty of the approach. Changes in groundwater storage near the observation wells can be represented by the changes in GWL with time $(\mathrm{dWT} / \mathrm{d} t)$. The changes in storage are controlled by the net inflow or outflow of nearby groundwater $(r(t)[L / T])$ and $\mathrm{ET}_{\mathrm{G}}$ :

$$
S_{\mathrm{y}}^{*} \frac{\mathrm{dWT}}{\mathrm{d} t}=r(t)-\mathrm{ET}_{\mathrm{G}}(t)
$$

where $S_{\mathrm{y}}$ is the specific yield.

When $\mathrm{ET}_{\mathrm{G}}$ is zero, equation (1) can be simplified as follows:

$$
S_{\mathrm{y}}^{*} \frac{\mathrm{dWT}}{\mathrm{d} t}=r(t)
$$

The recharge rate is a function of time [33]. Loheide [32] assumed that the head of the recharge source was constant. Thus, the recharge rate of an observation well can be obtained from the observed water table records, as expressed in equation (2):

$$
r(\mathrm{WT})=S_{\mathrm{y}}^{*} \frac{\mathrm{dWT}}{\mathrm{d} t} .
$$

The method assumes that the head of the recovery recharge has a similar change trend as the observed water table record; therefore, the trend included in the GWL can be removed as follows:

$$
\mathrm{WT}_{\mathrm{DT}}(t)=\mathrm{WT}(t)-m_{\mathrm{T}} \times t-b_{\mathrm{T}},
$$

where $\mathrm{WT}_{\mathrm{DT}}(t)$ is the detrended GWL, WT $(t)$ is the observed GWL, $m_{\mathrm{T}}$ is the trendline slope, and $b_{\mathrm{T}}$ is the trendline intercept.

$\Gamma\left(\mathrm{WT}_{\mathrm{DT}}\right)$ is a function of $\mathrm{dWT}_{\mathrm{DT}} / \mathrm{d} t$ and $\mathrm{WT}_{\mathrm{DT}}(t)$, and a best-fit estimate of the function can be obtained based on the detrended GWL from 00:00 to 06:00 of the day of interest and the following day. Then, to obtain the recharge rate function,

$$
r(t)=S_{\mathrm{y}}^{*} \times\left[\Gamma(\mathrm{WT}(t))+m_{\mathrm{T}}\right] .
$$

Finally, $\mathrm{ET}_{\mathrm{G}}$ is calculated as

$$
\mathrm{ET}_{\mathrm{G}}(t)=r(t)-S_{\mathrm{y}}^{*} \times \frac{\mathrm{dWT}}{\mathrm{d} t} .
$$

The estimated uncertainty of $S_{\mathrm{y}}$ (specific yield) is the major factor that causes $\mathrm{ET}_{\mathrm{G}}$ estimation errors $[23,34]$. The simulation experiments conducted by Loheide et al. [35] to estimate $S_{\mathrm{y}}$ demonstrated that diurnal GWL fluctuations and antecedent moisture conditions had almost no influence on $S_{\mathrm{y}}$. Furthermore, Meyboom [36] suggested that the readily available $S_{y}$ value should be half of the standard definition for $S_{y}$, whereas Loheide et al. [35] thought the suggestion should be based on the specific situation. To obtain the $S_{\mathrm{y}}$ value of the study area, soil samples at two depth ranges (0-0.8 $\mathrm{m}$ and $0.8-1.5 \mathrm{~m}$ below the ground) were collected. The soil moisture curve of the soil samples was determined using a pressure plate extractor (Daiki-3404; Daiki Rika Kogyo Co., Ltd, Saitama, Japan) to obtain important parameters used in the van Genuchten model, and the properties of the soil samples were analyzed using a Mastersizer 2000 laser diffractometer (Malvern Panalytical, Malvern, UK). The gravel (>2 mm), sand (0.0625-2 mm), silt $(0.004-0.0625 \mathrm{~mm})$, and clay $(<0.004 \mathrm{~mm})$ contents of the $0-0.8 \mathrm{~m}$ soil sample were $0,98.63,1.37$, and $0 \%$ and those of the $0.8-1.5 \mathrm{~m}$ sample were $0,78.58,19.10$, and $2.32 \%$, respectively. The van Genuchten parameters $\theta_{r}$ (unitless), $\theta_{s}$ (unitless), $\alpha\left(\mathrm{cm}^{-1}\right)$, and $n$ (unitless) for the $0-0.8 \mathrm{~m}$ sample were $0.0291,0.3873,0.0425$, and 2.363 and those for the $0.8-1.5 \mathrm{~m}$ sample were $0.0153,0.3732,0.0259$, and 1.753, respectively. The $S_{y}$ estimation method proposed by Crosbie et al. [37] was used:

$$
\begin{array}{r}
\mathrm{S}_{\mathrm{y}}=S_{\mathrm{yu}}-\frac{\mathrm{S}_{\mathrm{yu}}}{\left[1+\left(\alpha\left(\left(z_{i}+z_{f}\right) / 2\right)^{n}\right)\right]^{1-(1 / n)}}, \\
S_{\mathrm{yu}}=\theta_{s}-\theta_{r},
\end{array}
$$

where $\theta_{s}$ is the soil saturated moisture content, $\theta_{r}$ is the residual moisture content, $z_{i}$ and $z_{f}$ are the initial and final DTWT, and $\alpha$ and $n$ are parameters in the van Genuchten model.

\section{Results and Discussion}

3.1. Relationship between Diurnal GWL Fluctuations and Vegetation. From the observed water table records, regular diurnal GWL fluctuations were detected at eight groundwater observation sites, except wells G1 and G2, which were almost entirely comprised of bare sand (Table 1). The observation sites where the fluctuations were detected were covered with various types of vegetation (see Table 1 for main vegetation types). This phenomenon emerged from May to October, which was consistent with the growing season of the desert lakeside vegetation at the observation sites (see Figure 2(d) for wells G6 and G8). The findings mentioned above indicated that the diurnal GWL fluctuations were related to the vegetation covering lakeside areas.

On a daily scale, the diurnal GWL fluctuations exhibited a characteristics pattern whereby the water table decreased continuously during the daytime and rose gradually at night, 
TABLE 1: Classification of observation sites based on diurnal groundwater level fluctuations and the main vegetation profiles near the observation sites.

\begin{tabular}{lccccccccrr}
\hline Well no. & \multicolumn{2}{c}{$\begin{array}{l}\text { No diurnal } \\
\text { fluctuation }\end{array}$} & \multicolumn{4}{c}{ Diurnal fluctuation detected } \\
& G1 & G2 & G3 & G4 & G5 & G6 & G7 & G8 & G9 & G10 \\
\hline Main vegetation type & Bare sand & PA & PA & PA & AS & AS & NT and AS & NT and AS & NT and AS \\
\hline
\end{tabular}

PA: Phragmites australis; AS: Achnatherum splendens; NT: Nitraria tangutorum.

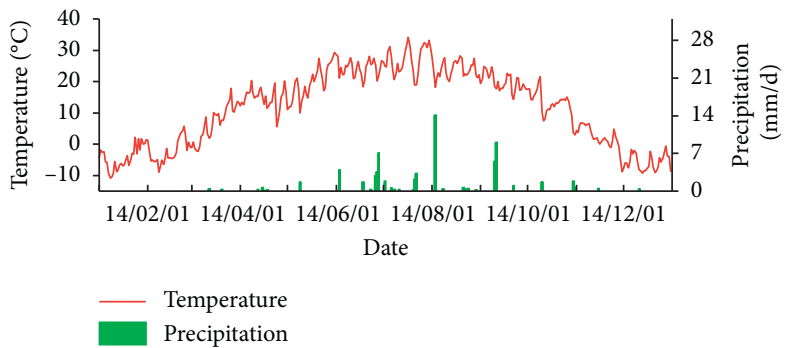

(a)

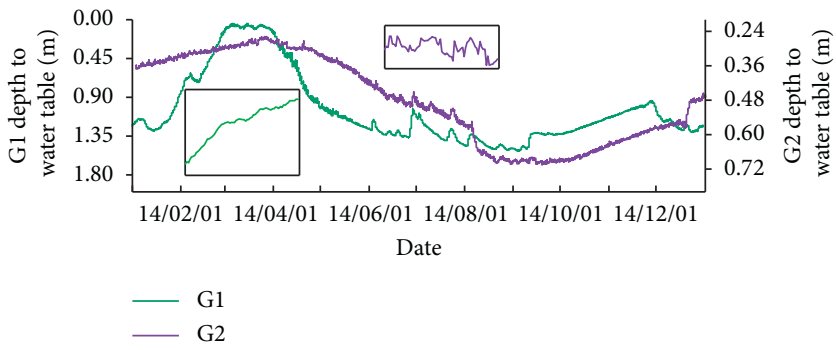

(c)

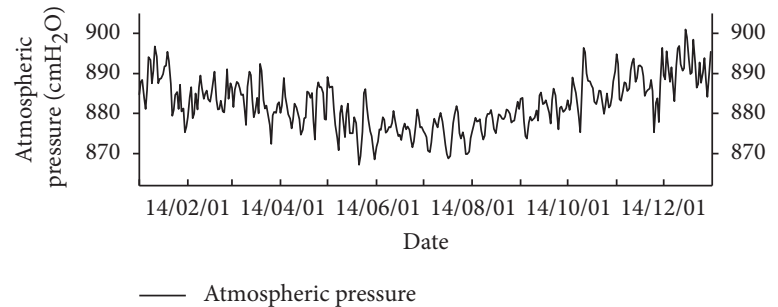

(b)

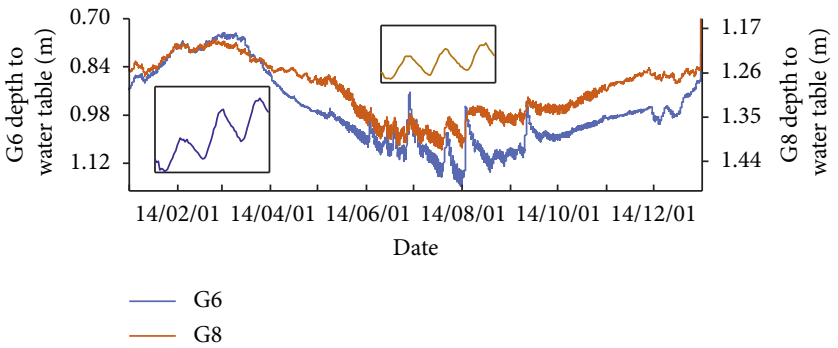

(d)

FIGURE 2: Daily temperature, precipitation, atmospheric pressure, and hourly groundwater level (GWL) fluctuations at observation sites G1, G2, G6, and G8 in 2014: (a) temperature and precipitation; (b) atmospheric pressure; (c) GWL fluctuations at observation sites G1 and G2, where no regular diurnal fluctuations were detected; (d) GWL fluctuations at observation sites G6 and G8, where regular diurnal fluctuations were detected. The insets in (c) and (d) are derived from the corresponding groundwater level from June 5 to June 8.

reaching a maximum in the morning and a minimum in the afternoon. This diel cycle is generally thought to be induced by regular daily water consumption of phreatophytes, which essentially represents the dynamic balance between the groundwater lateral recharge and the consumption of groundwater by vegetation $[6,38-40]$. On a seasonal scale, there were variations in diurnal GWL fluctuations at the eight sites, which was attributed to the interaction of vegetation with the surrounding environments $[1,7,41]$. To further understand the relationship between the diurnal GWL fluctuations and the vegetation at the observation sites on a seasonal scale, the diurnal GWL fluctuations during rainless periods at observation sites G4, G6, and G9 in different months are illustrated in Figure 3. In mid-April, the diurnal GWL fluctuations of the three observation sites were not obvious due to the low temperature (daily average maximum and minimum temperature: $20.0^{\circ} \mathrm{C}$ and $3.9^{\circ} \mathrm{C}$ ) and no germinative vegetation. Figure 3 illustrates evident diurnal GWL fluctuations from June to September when desert vegetation was in the growth stage and large amounts of groundwater were consumed. The diurnal GWL fluctuations in July were more obvious at observation sites G6 and G9, although the DTWT in July was higher compared with that in June, showing a larger amplitude of diurnal GWL fluctuations in July. The meteorological conditions in July that drove higher vegetation transpiration (daily average maximum and minimum temperature: $33.5^{\circ} \mathrm{C}$ and $17.3^{\circ} \mathrm{C}$ ) could account for mentioned observations. At the end of November, the vegetation entered the dormant period and the diurnal GWL fluctuations decreased because of the lower temperature in the desert (daily average maximum and minimum temperature: $8.9^{\circ} \mathrm{C}$ and $-6.7^{\circ} \mathrm{C}$ ).

The diurnal GWL fluctuations exhibited variations among the observation sites. As illustrated in Figure 3, the amplitudes of diurnal GWL fluctuations at observation site G4 from June to September were larger than those of observation sites G6 and G9. To have a full understanding of these variations, the amplitudes of diurnal GWL fluctuations of each observation site in the vegetation growing season and nongrowing season were plotted as separate boxplots (Figure 4). Observation sites G3-G10 (with vegetation cover) had larger amplitudes of diurnal GWL fluctuations in the growing season, but the amplitudes in the nongrowing season were negligible. At sites G1 and G2 (the bare sand sites), no evident diurnal GWL fluctuations were observed in either the vegetation growing season or the nongrowing 


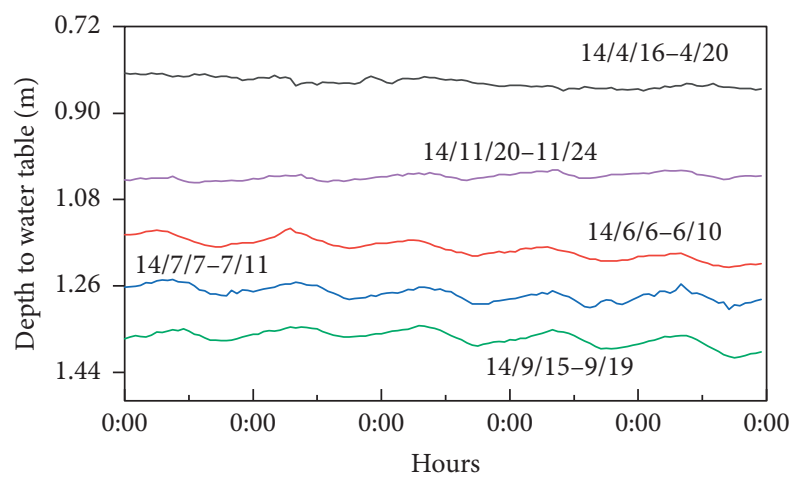

(a)

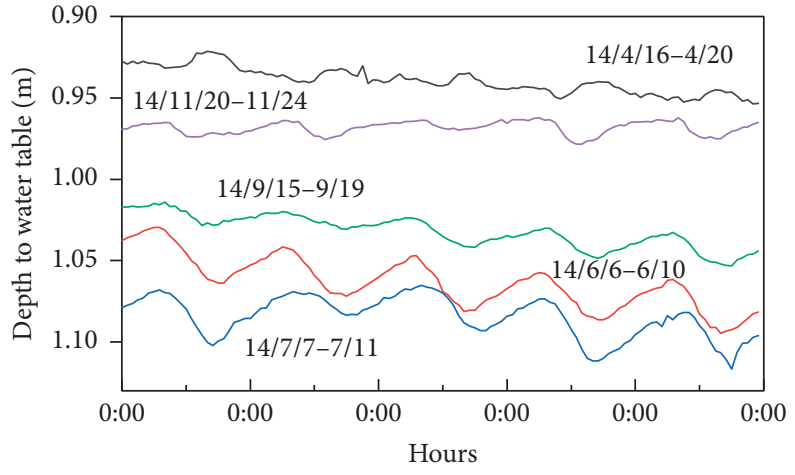

(b)

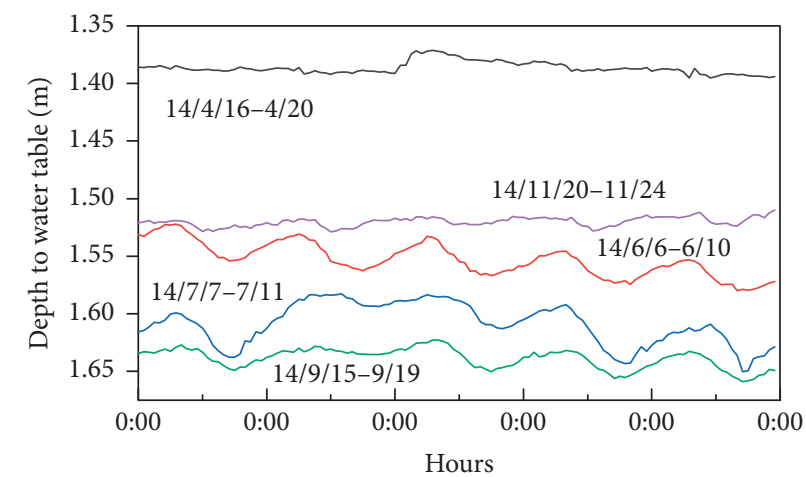

(c)

FIGURE 3: Seasonal variations in diurnal groundwater level fluctuations at observation site (a) G4, (b) G6, (c) G9.

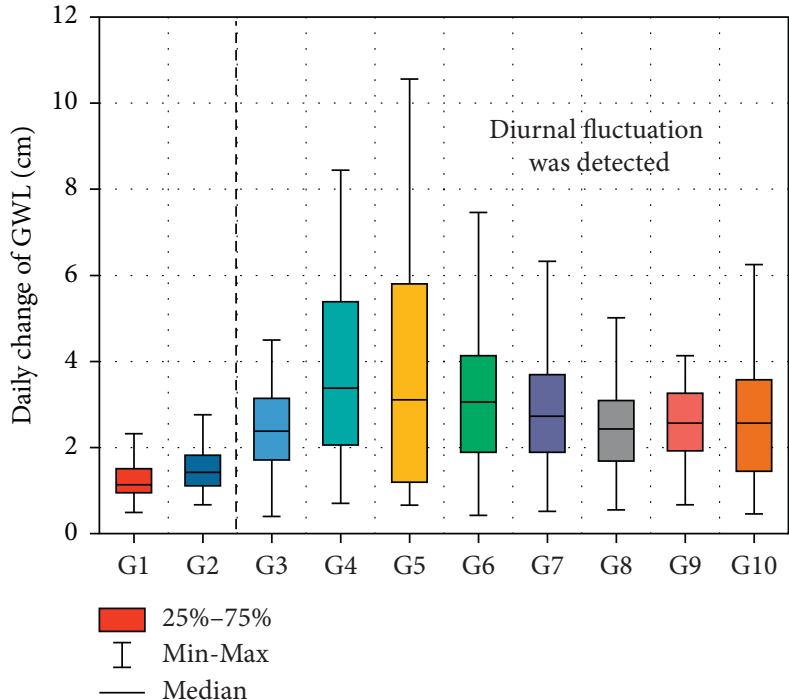

(a)

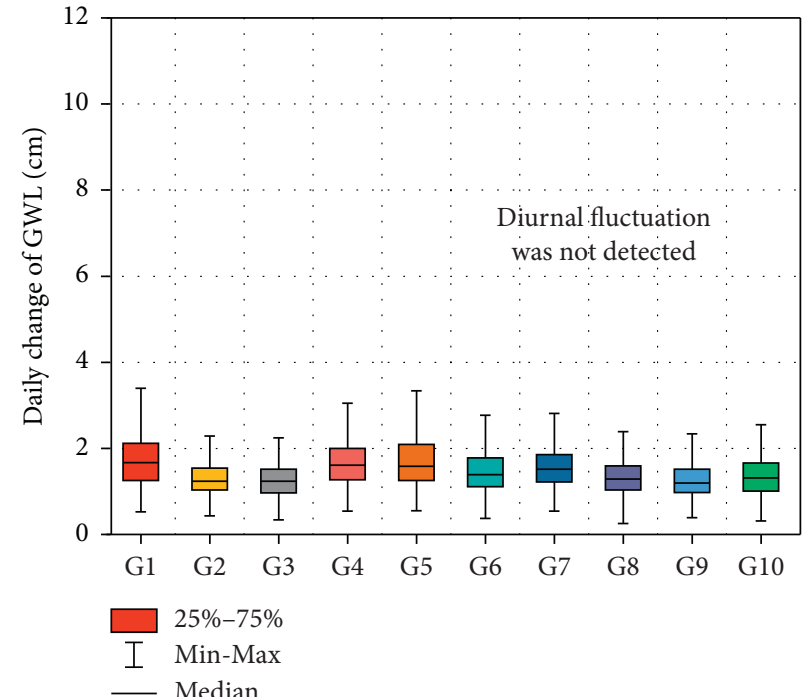

(b)

FIGURE 4: Comparison of boxplots of the amplitude in groundwater level (GWL) during the (a) growing season and (b) nongrowing season. The vertical dashed line in (a) separates sites with no regular diurnal GWL fluctuations (G1 and G2) and those with fluctuations (G3-G10); no fluctuations were detected in (b).

season. Furthermore, the amplitudes of diurnal GWL fluctuations in the growing season varied among the sites G3-G10, which was attributed to the vegetation type. For instance, the amplitudes at sites G4 and G5, mainly covered by Phragmites australis, were larger than those of the sites G6-G10, with Achnatherum splendens and Nitraria tangutorum. Interestingly, site G3, also mainly covered with Phragmites australis, had a smaller amplitude of diurnal 
GWL fluctuations than sites G4 and G5, indicating that vegetation type was not the only factor determining the variations in diurnal GWL fluctuations. Thus, climatic conditions, soil properties, and groundwater dynamic processes might also cause differences in water consumption and recharge balance, manifesting as a spatial difference in diurnal GWL fluctuations.

3.2. Estimation of $E T_{G}$ under Three Vegetation Covers. The White method was used to estimate the $\mathrm{ET}_{\mathrm{G}}$ rate of observation sites with three vegetation covers. The GWL records of observation sites G3-G10 during the vegetation growing season were selected to analyze the $\mathrm{ET}_{\mathrm{G}}$ rate, and the statistical results are summarized in Table 2 . The $\mathrm{ET}_{\mathrm{G}}$ rate was associated with vegetation type, especially in the middle of the growing season. From the relationship between vegetation type and the daily average $\mathrm{ET}_{\mathrm{G}}$ rate, the observation sites could be grouped into three categories: the $\mathrm{ET}_{\mathrm{G}}$ rate at sites G4 and G5, with well-grown Phragmites australis coverage, was $\sim 5 \mathrm{~mm} / \mathrm{d}$; the daily average $\mathrm{ET}_{\mathrm{G}}$ of observation sites G6 and G7 dominated by Achnatherum splendens coverage was $3 \sim 4 \mathrm{~mm}$, including site $\mathrm{G} 7$ with the best vegetation coverage in this category, where the $\mathrm{ET}_{\mathrm{G}}$ rate reached $4 \mathrm{~mm} / \mathrm{d}$; the remaining three observation sites G8-G10 were mainly covered by Nitraria tangutorum, and the daily average $\mathrm{ET}_{\mathrm{G}}$ rate was relatively low. Overall, the order of groundwater consumption by the three vegetation covers in this study was Phragmites australis $>$ Achnatherum splendens $>$ Nitraria tangutorum. These results were consistent with the $\mathrm{ET}_{\mathrm{G}}$ rate of similar research areas. For instance, an area covered with Salix psammophila in the Mu Us Desert, China, had a DTWT of 1 1.5 m and daily $\mathrm{ET}_{\mathrm{G}}$ rate of $3 \sim 4 \mathrm{~mm}$ in the growing season [42], which was similar to the estimates for the observation sites with Nitraria tangutorum and Achnatherum splendens in this study. This similarity supports the accuracy of the estimated results in representing the $\mathrm{ET}_{\mathrm{G}}$ rate of desert lakeside vegetation.

In this study, $\mathrm{ET}_{\mathrm{G}}$ rates were also related to vegetation vitality. For example, site G3 with Phragmites australis, compared with sites G4 and G5 with similar vegetation, had poorer vegetation conditions with sparse patches and weak viability. As mentioned above, the amplitudes of diurnal GWL fluctuations at this site were narrower, which were ultimately reflected in a lower $\mathrm{ET}_{\mathrm{G}}$ rate than that at sites G4 and G5. Other sites also showed a similar situation, which was reflected in the maximum daily $\mathrm{ET}_{\mathrm{G}}$ rate. Observation site $\mathrm{G} 3$ only had a maximum daily $\mathrm{ET}_{\mathrm{G}}$ rate of $6.2 \mathrm{~mm} / \mathrm{d}$, which was similar to that of observation sites with Nitraria tangutorum. In contrast, the maximum daily $\mathrm{ET}_{\mathrm{G}}$ rate at site G6, with Achnatherum splendens, reached $11.3 \mathrm{~mm} / \mathrm{d}$, which was slightly lower than that of the sites with well-grown Phragmites australis.

On a seasonal scale, $\mathrm{ET}_{\mathrm{G}}$ is controlled by vegetation phenology [7]. In this study, the estimated $\mathrm{ET}_{\mathrm{G}}$ was higher from July to August than in other stages of the growing season (Figure 5). Moreover, the period during which the peak daily mean $\mathrm{ET}_{\mathrm{G}}$ occurred was not perfectly consistent among the observation sites. The highest daily mean $\mathrm{ET}_{\mathrm{G}}$ at G3, G6, G9, and G10 occurred in early July, whereas the $\mathrm{ET}_{\mathrm{G}}$ rates of observation sites G4 and G7 were markedly higher from mid-July to early September than other growth stages. This indicated that the optimal growth periods varied among sites with different vegetation types and vitality. Due to the better vegetation coverage and growth condition of sites G4 and G7, the vegetation maintained relatively good growth and consumed large amounts of groundwater even when the vegetation in other sites entered their final growth stage in September. To explain the discrepancy, a previous study suggested that differences in the types of deciduous and nondeciduous vegetation led to different periods reaching a maximum $\mathrm{ET}_{\mathrm{G}}$ [43]. The vegetation in the present study comprised herbaceous and small shrub plants, with different vegetation coverages from those of the study mentioned above. Thus, it is logical that the unsynchronized maximum daily mean $\mathrm{ET}_{\mathrm{G}}$ was driven mainly by vegetation type and growth vitality.

3.3. Controlling Factors of $E T_{G}$ Rate. Vegetation type, meteorological parameters, and groundwater dynamics jointly led to spatiotemporal variations in the diurnal GWL fluctuations at the observation sites, which ultimately was reflected in the $\mathrm{ET}_{\mathrm{G}}$. To further explore the key factors affecting the $\mathrm{ET}_{\mathrm{G}}$ rate at the observation sites and the mechanisms that control $\mathrm{ET}_{\mathrm{G}}$ in the Badain Jaran Desert, the relationship between $\mathrm{ET}_{\mathrm{G}}$ rate with DTWT and meteorological parameters was analyzed. Taking observation site G6 as an example (Figure 6), there was a significant positive correlation between $\mathrm{ET}_{\mathrm{G}}$ rate and air temperature, which was consistent with the result that temperature was the key factor controlling the seasonal-scale variations in the diurnal GWL fluctuations obtained from Figure 3. Moreover, the $\mathrm{ET}_{\mathrm{G}}$ rate at site $\mathrm{G} 6$ was positively correlated with solar radiation but had no significant relationship with wind speed, relative humidity, and other factors. These results indicated that air temperature and solar radiation are the key meteorological factors controlling the $\mathrm{ET}_{\mathrm{G}}$ rate at this observation site.

The relationship between the $\mathrm{ET}_{\mathrm{G}}$ rate and the external factors at site G6 indicated that the meteorological conditions in the Badain Jaran Desert were among the most critical factors controlling the $\mathrm{ET}_{\mathrm{G}}$ rate. To verify this conclusion, the relationship between $\mathrm{ET}_{\mathrm{G}}$ rate and PET at eight observation sites (i.e., as a comprehensive measure of meteorological condition) were investigated. Significant positive correlations $\left(R^{2}=0.38 \sim 0.54\right)$ were observed at all sites except G7 (Figure 7), which demonstrated the influence of meteorological factors on $\mathrm{ET}_{\mathrm{G}}$ rate. For comparison, a previous study in a semi-arid area suggested that $\mathrm{ET}_{\mathrm{G}}$ was weakly positively correlated with PET $\left(R^{2}=0.02 \sim 0.32\right)[19]$, and Lautz [23] also reported a similar correlation between PET and $\mathrm{ET}_{\mathrm{G}}$ in a riparian region. In contrast, the $\mathrm{ET}_{\mathrm{G}}$ observed by Yuan et al. [18] showed a significant positive correlation with PET in desert riparian forests. Mazur et al. [17] also recognized a positive correlation and estimated the $\mathrm{ET}_{\mathrm{C}}$ (i.e., interpolated $\mathrm{ET}$ rate) based on the significant relationship between the estimated $\mathrm{ET}_{\mathrm{G}}$ and PET when the White method was not appropriate for $\mathrm{ET}_{\mathrm{G}}$ estimation. Therefore, the correlation between the estimated $\mathrm{ET}_{\mathrm{G}}$ and PET differed among the observation sites and the 
TABLE 2: Statistics of the estimated groundwater evapotranspiration $\left(\mathrm{ET}_{\mathrm{G}}\right)$ of observation sites during the growing season in 2014, number of days used in the estimation, and the specific yield $\left(S_{\mathrm{y}}\right)$.

\begin{tabular}{|c|c|c|c|c|c|c|c|}
\hline \multirow{2}{*}{ Well no. } & \multirow{2}{*}{ Number of days } & \multicolumn{5}{|c|}{$\mathrm{ET}_{\mathrm{G}}(\mathrm{mm})$} & \multirow{2}{*}{$S_{\mathrm{y}}$} \\
\hline & & Total & Daily mean & Daily max. & Daily min. & SD & \\
\hline G3 & 169 & 568.7 & 3.4 & 6.2 & 0.3 & 1.5 & 0.18 \\
\hline G4 & 158 & 784.9 & 5.0 & 11.0 & 0.1 & 2.6 & 0.21 \\
\hline G5 & 149 & 757.4 & 5.1 & 13.2 & 0.3 & 3.2 & 0.22 \\
\hline G6 & 160 & 566.4 & 3.5 & 11.3 & 0.3 & 1.8 & 0.20 \\
\hline G7 & 160 & 667.2 & 4.0 & 8.3 & 0.6 & 1.7 & 0.23 \\
\hline G8 & 182 & 538.0 & 2.9 & 6.0 & 0.2 & 1.3 & 0.22 \\
\hline G9 & 154 & 590.1 & 3.8 & 7.9 & 0.1 & 2.1 & 0.23 \\
\hline G10 & 165 & 494.7 & 3.0 & 5.3 & 0.1 & 1.1 & 0.19 \\
\hline
\end{tabular}
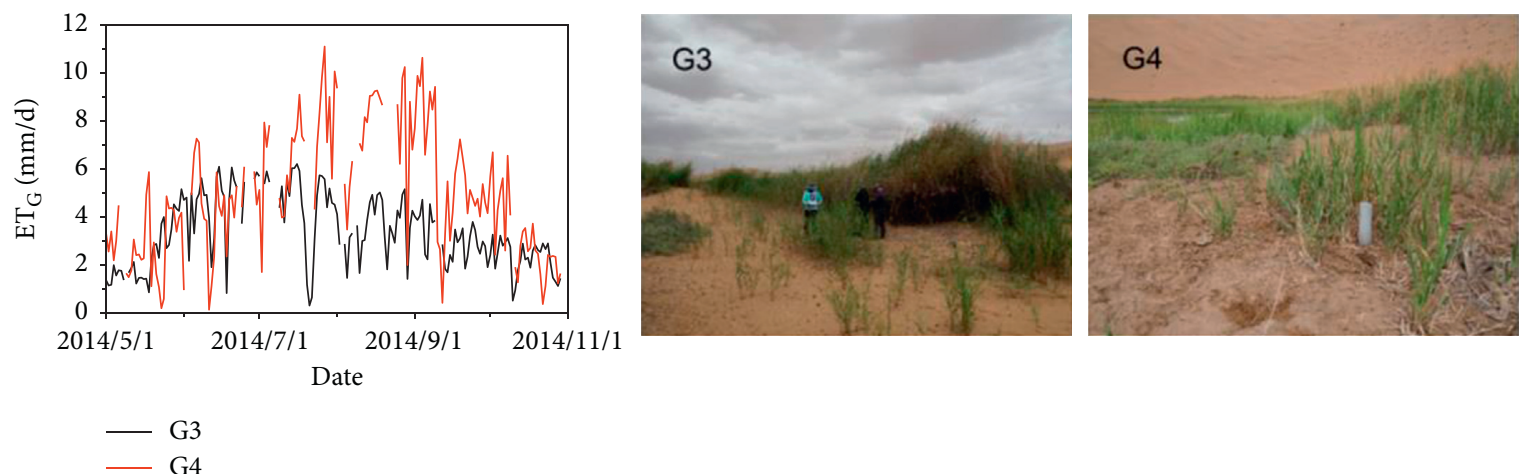

(a)
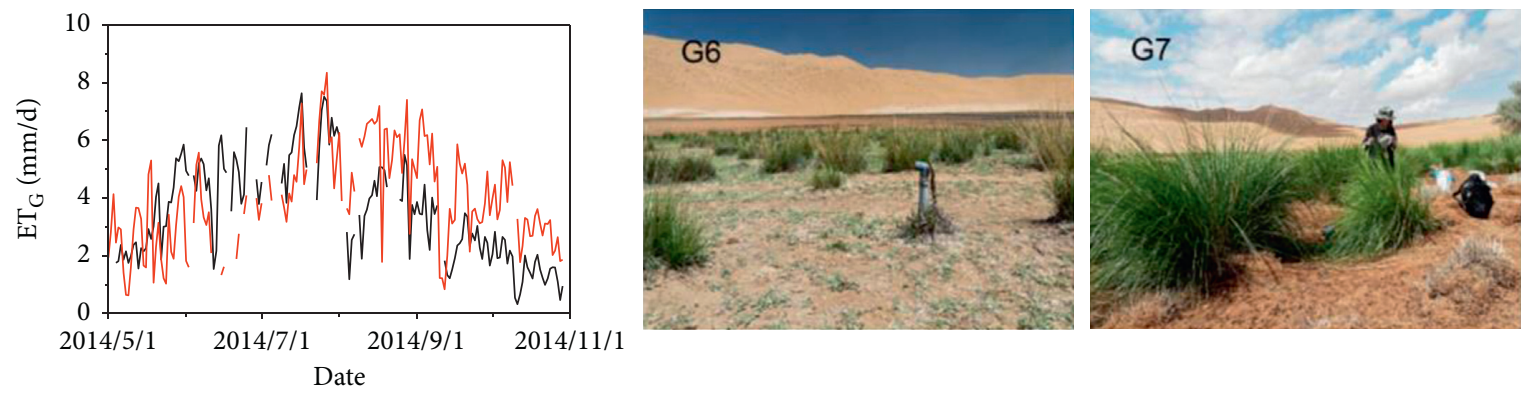

- G6

- G7
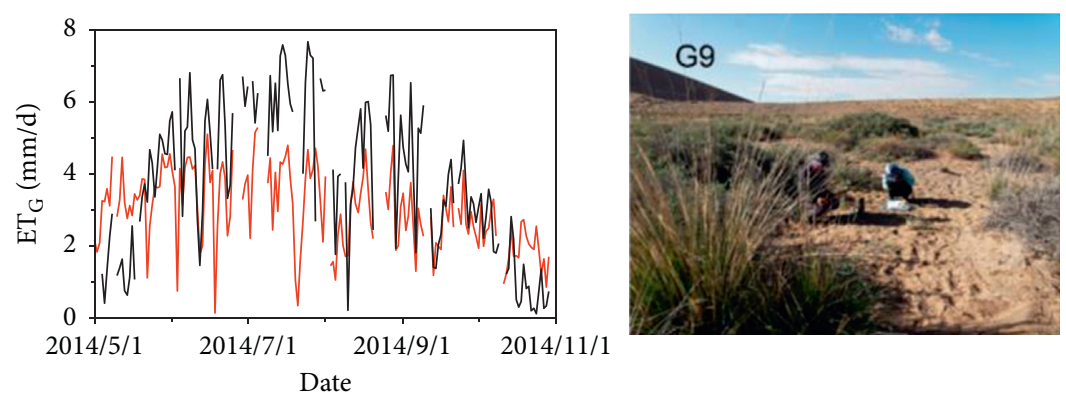

- G9

- G10

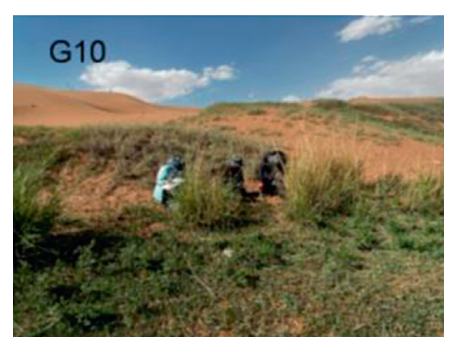

(b)

(c)

FIGURE 5: Estimated daily groundwater evapotranspiration ( $\mathrm{ET}_{\mathrm{G}}$ ) of observation sites: (a) G3 and G4, (b) G6 and G7, and (c) G9 and G10 with different vegetation covers. 


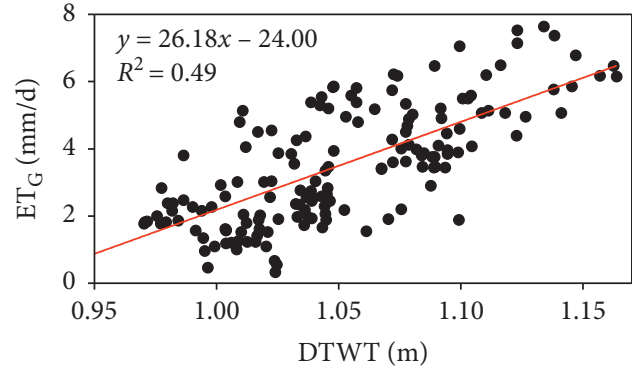

(a)

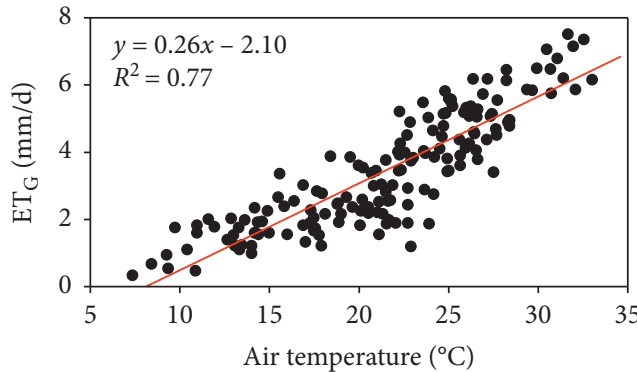

(c)

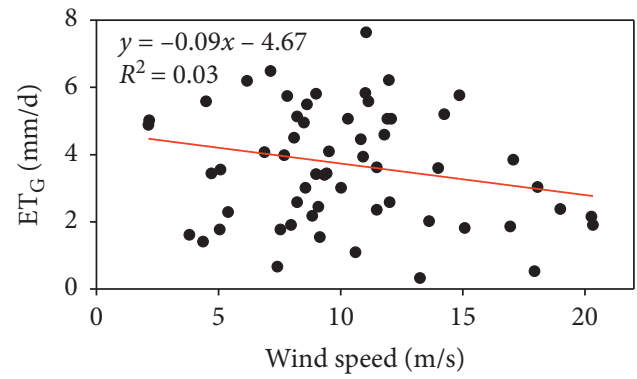

(e)

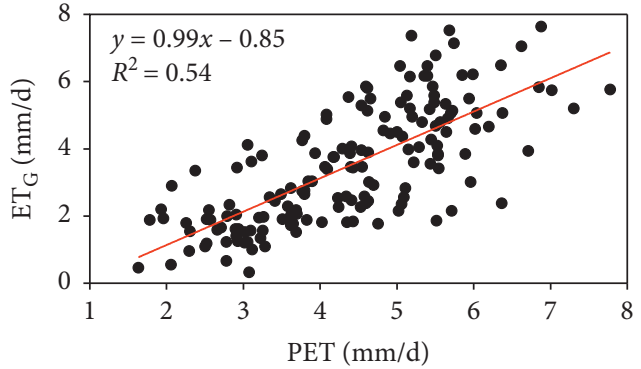

(b)

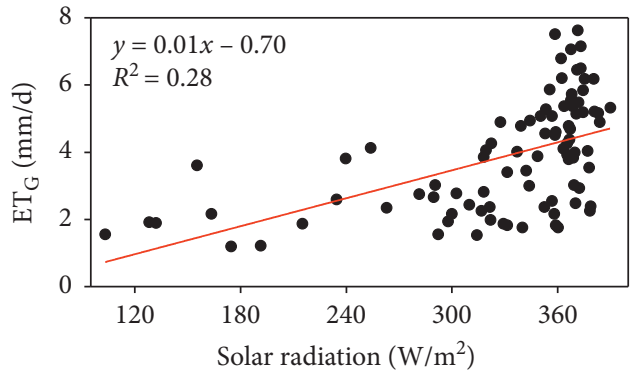

(d)

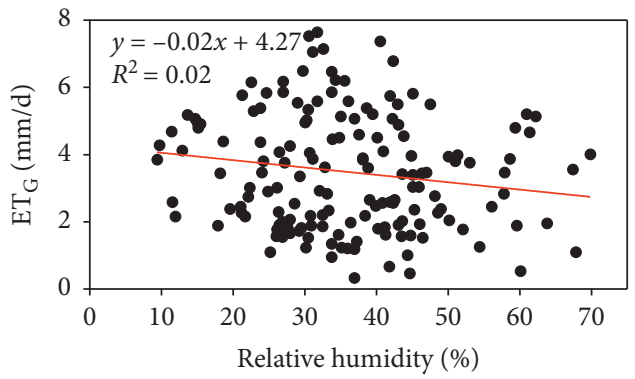

(f)

FIGURE 6: Relationship of diurnal groundwater level fluctuations with depth to water table (DTWT), potential evapotranspiration (PET), air temperature, solar radiation, wind speed, and relative humidity at observation site G6.

relationship between the two should be explored before applying the estimation method by Mazur et al. [17].

In this study, estimated $\mathrm{ET}_{\mathrm{G}}$ and PET showed relatively high correlations at most observation sites, and there were few precipitation events. Therefore, the White and Mazur's estimation methods could be jointly used to quantify the annual groundwater consumption (see Figure 8 for the estimated results at observation site G6). Observation sites G3, G5, G6, G8, G9, and G10 were selected for this application based on the significant relationships between the estimated $\mathrm{ET}_{\mathrm{G}}$ and PET, where the total $\mathrm{ET}_{\mathrm{G}}$ in the whole growing season (total 184 days) was obtained. The $\mathrm{ET}_{\mathrm{G}}$ ranged from 600 to $900 \mathrm{~mm}$ at observation sites with Phragmites australis and varied depending on the coverage conditions, and it ranged from approximately 600 to $650 \mathrm{~mm}$ at the sites covered with Achnatherum splendens. At sites with Nitraria tangutorum and Achnatherum splendens, the $\mathrm{ET}_{\mathrm{G}}$ ranged from 500 to $650 \mathrm{~mm}$.

In general, the amount of groundwater available for vegetation roots decreases as DTWT increases, resulting in a negative relationship between DTWT and $\mathrm{ET}_{\mathrm{G}}$ rate [44]. Furthermore, Cooper et al. [45] found that a $1.6 \mathrm{~m}$ water level decline resulted in a $62 \%$ reduction in $\mathrm{ET}_{\mathrm{G}}$, highlighting the impact DTWT changes on $\mathrm{ET}_{\mathrm{G}}$. In this study, the DTWT range varied among the observation sites, and their relationships with vegetation type, vegetation vitality, and evapotranspiration rate were consistent with the trends observed by Jackson et al. [44]. For instance, observation sites G4 and G5, which were mainly covered densely with Phragmites australis, had a DTWT of 0.7 1.5 m. Meanwhile, sites G8 and G9 covered sparsely with Nitraria tangutorum, had a DTWT of $1.2 \sim 1.7 \mathrm{~m}$. Correspondingly, under the same meteorological conditions, the $\mathrm{ET}_{\mathrm{G}}$ rate of the sites with Phragmites australis was markedly higher than that of sites with Nitraria tangutorum.

The estimated total $\mathrm{ET}_{\mathrm{G}}$ at each observation site in the growing season was greater than the total annual precipitation in that year $(103.7 \mathrm{~mm})$, but there was no difference in the DTWT at the beginning and end of the growing season. Overall, the water level first declined and then returned to the original level (Figure 9), indicating that groundwater was the primary recharge source of the lakes in this study area, with only a small amount of precipitation recharge. Furthermore, the total amount of lateral recharge and 


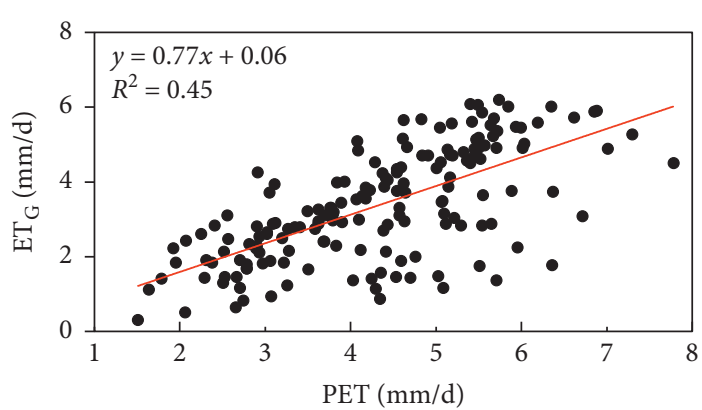

(a)

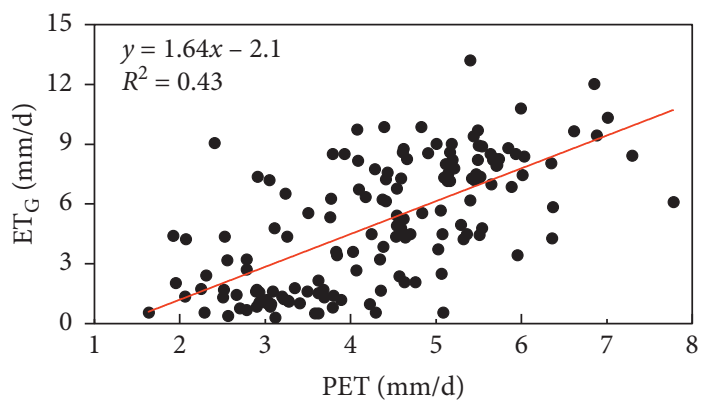

(c)

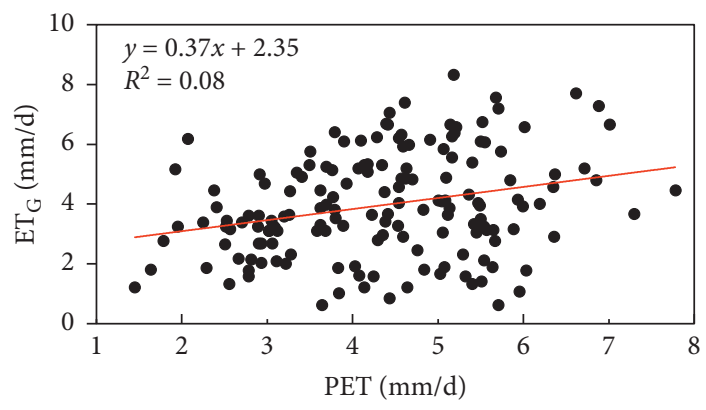

(e)

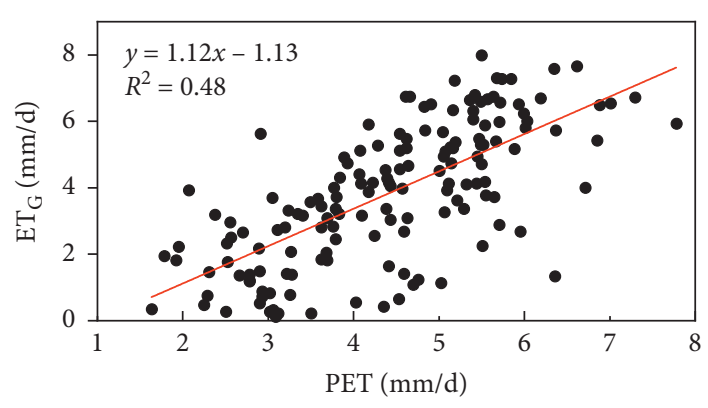

(g)

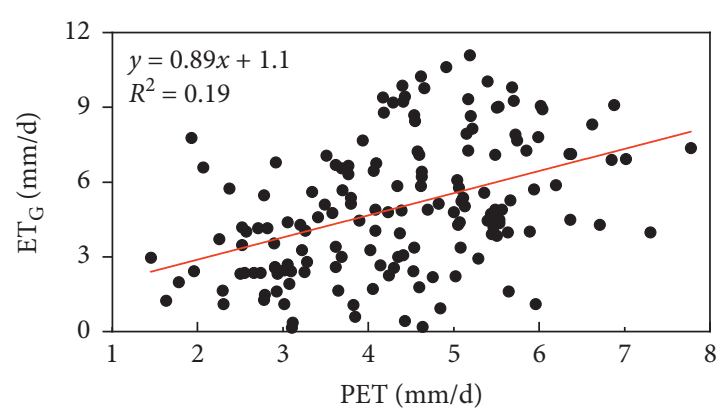

(b)

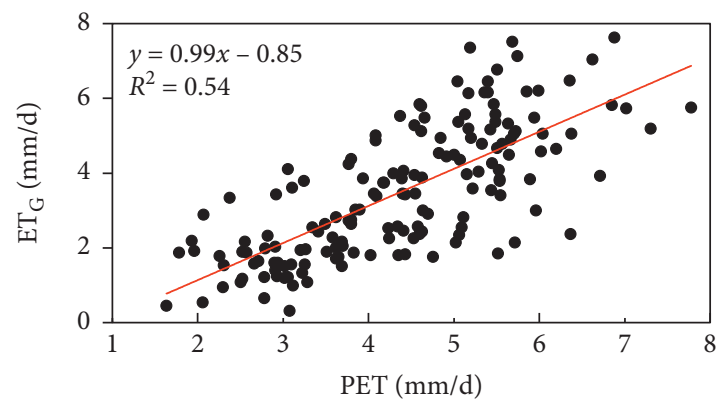

(d)

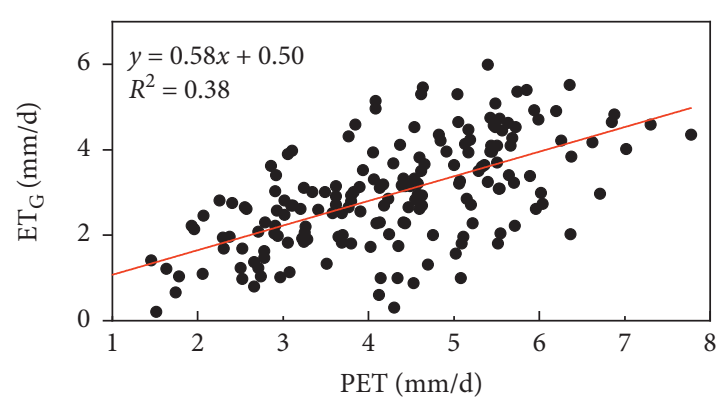

(f)

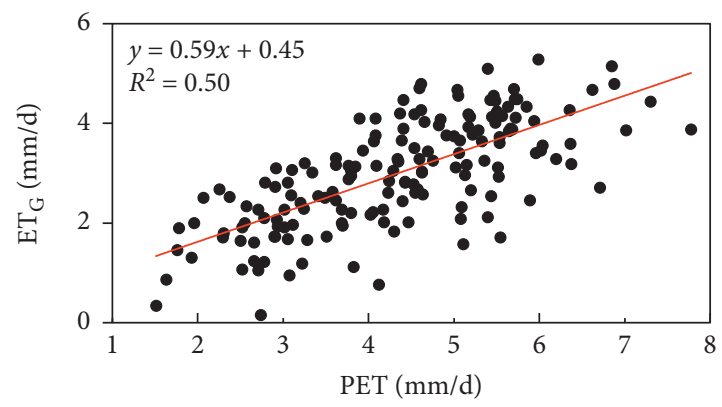

(h)

FIGURE 7: Relationship between the estimated daily groundwater evapotranspiration $\left(\mathrm{ET}_{\mathrm{G}}\right)$ and potential evapotranspiration (PET) at the eight observation sites with vegetation coverage. (a) G3, Phragmites australis (DTWT: 0.74-1.05 m). (b) G4, Phragmites australis (DTWT: 0.83-1.45 m). (c) G5, Phragmites australis (DTWT: 0.75-1.45 m). (d) G6, Achnatherum splendens (DTWT: 0.97-1.15 m). (e) G7, Achnatherum splendens (DTWT: 1.19-1.55 m). (f) G8, Nitraria tangutorum and Achnatherum splendens (DTWT: 1.27-1.39 m). (g) G9, Nitraria tangutorum and Achnatherum splendens (DTWT: 1.43-1.69 m). (h) G10, Nitraria tangutorum and Achnatherum splendens (DTWT: $0.86-1.05 \mathrm{~m})$.

precipitation recharge of groundwater was greater than the total $\mathrm{ET}_{\mathrm{G}}$. Therefore, groundwater is the main water source for vegetation growth in this case, and the $\mathrm{ET}_{\mathrm{G}}$ process is dependent on groundwater recharge. However, a positive correlation was indicated between $\mathrm{ET}_{\mathrm{G}}$ rate and DTWT at observation site G6 (Figure 6), and the water table decreased by $\sim 0.2 \mathrm{~m}$ from May to August, while the estimated $\mathrm{ET}_{\mathrm{G}}$ showed an increasing trend (Figure 9). This seemingly contradictory phenomenon can be explained by the fact that the $\mathrm{ET}_{\mathrm{G}}$ rate was jointly controlled by the DTWT and PET, 


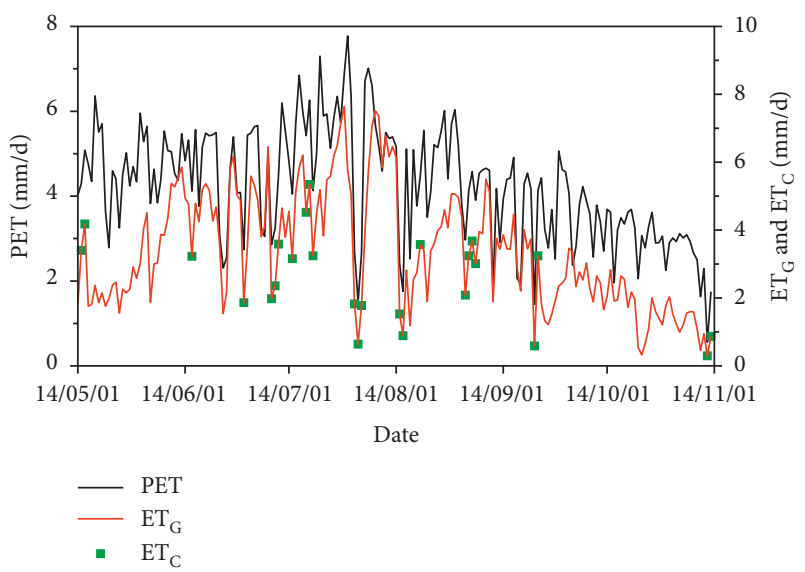

FIgURE 8: Estimated groundwater evapotranspiration $\left(\mathrm{ET}_{\mathrm{G}}\right)$ and interpolated evapotranspiration rate $\left(\mathrm{ET}_{\mathrm{C}}\right)$ based jointly on the white and Mazur's methods and potential evapotranspiration (PET) at the observation site G6.

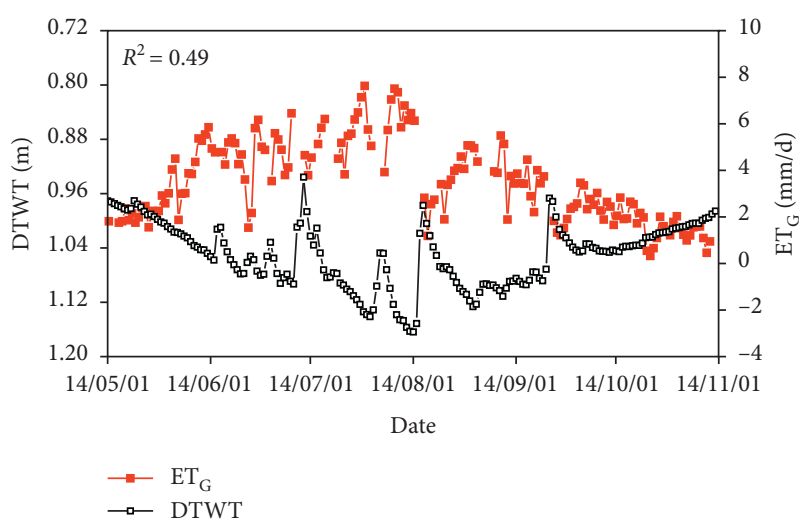

FIGURE 9: Estimated daily groundwater evapotranspiration $\left(\mathrm{ET}_{\mathrm{G}}\right)$ of observation site G6 and the depth to water table (DTWT) in the growing season in 2014.

and the effect of PET exceeded that of DTWT in that period. During the observed period in this study, changes in DTWT had no marked influence on the $\mathrm{ET}_{\mathrm{G}}$ rate because DTWTs were shallow (i.e., all within $2 \mathrm{~m}$ ) and presented relatively small changes, all within $2 \mathrm{~m}$. Therefore, observation sites with a wider DTWT range can be set up in future research to further discuss the influence of DTWT on the $\mathrm{ET}_{\mathrm{G}}$ rate.

\subsection{Limitations and Observations on Applying the Proposed} Method. The application of the White method and its revised methods are based on four basic assumptions: (1) reduction in GWL is induced only by vegetation; (2) the transpiration at night is weak and negligible; (3) the average raise rates of GWL at night can represent recharge rates of groundwater in a given day; (4) the specific yields are representative and reliable. Although the groundwater signal methods have been widely verified and applied in studies on vegetation evapotranspiration of arid regions, the assumptions still have certain limitations. These shortages are specifically reflected in the following scenarios: lateral GWL recharge rates change on a daily basis and there are errors in recharge rates using the constant rise rates of GWL at night; accurate specific yields are not easy to attain; with the advancement of high-frequency digital data collection devices, recent studies have found that transpiration of some vegetation did not stop completely at night $[5,46]$. To overcome these deficiencies, many studies proposed several revised methods. In regard to the calculation of groundwater recharge rates, Troxell [33] questioned whether recharge rates were constant on a daily basis. Later, scholars represented by Gribovszki et al. [14] and Loheide [32] proposed new methods to obtain the dynamic daily recharge rates, which improved the $\mathrm{ET}_{\mathrm{G}}$ estimation accuracy.

Considering the basic assumptions and their limitations, there are some observations to be explained in the application of the groundwater diurnal signal method in Badain Jaran Desert. Due to their diverse mechanisms, GWL diurnal fluctuations can be categorized into various types [40]. The GWL series are easily distinguished from each other except the cycles induced by atmospheric pressure and evapotranspiration, as the two have similar fluctuant shapes. Atmospheric pressure effects can also occur in unconfined aquifers typically mirroring each other [47-49]. The diurnal cycles induced by atmospheric pressure and evapotranspiration are both continuous time series. However, there are significant differences in their daily variations. The pressuredominated GWL cycles are closely related to the fluctuations of atmospheric pressure in each season, and the valley and peak values of GWL correspond to the maximum and minimum air pressure throughout the day, respectively. Similar to the GWL diurnal fluctuations observed by Jiang et al. [50], air pressure reached a maximum at approximately 10:00 am each day when the water level was the lowest. Conversely, the pressure was lowest at 3:00 pm when GWL reached its maximum. In the case of the Badain Jaran Desert, diurnal GWL fluctuations are completely different from the above type and are consistent with the ET-diurnal cycles [40].

The second assumption in the White method (i.e., the transpiration of vegetation at night is negligible) can be confirmed by comparing the results in this study with other research results in nearby desert areas. For example, Yuan et al. [18] thought that groundwater evapotranspiration at night was weak based on observations using the eddy covariance method in areas covered by desert vegetation. The site chosen for observation was dominated by Tamarix, where Phragmites australis, Glycyrrhiza inflata, and other types also grow, which was rather similar to the observation sites in this study. Additionally, other studies based on the White method estimated groundwater evapotranspiration in regions of $\mathrm{Mu}$ Us and Gobi Deserts that were covered with vegetation $[11,42,43]$. Although vegetation transpiration at night could be negligible in most cases, other studies have determined that transpiration at night is considerable in certain environments. Therefore, the $\mathrm{ET}_{\mathrm{G}}$ estimation in these cases is based on the reliability of the assumption. In future research, it is necessary to monitor the vegetation water consumption at night to reduce the $\mathrm{ET}_{\mathrm{G}}$ estimation uncertainty. 
Methods to obtain aquifer specific yields are also important in research involving the White method. Specific yields are not only related to the aquifer soil texture but also affected by the depth to water table, dynamic rates of temporal change of GWL, and drainage time. There are various methods based on factual research conditions aiming to obtain a representative and reliable specific yield. Gribovszki [51] recently proposed a diurnal method to obtain dynamic specific yield and compared it with traditional specific yield estimation techniques. Moreover, pumping test estimations are considered to be a relatively low-cost and suitable method, as it is the most similar to the dynamic specific yield. While it would be difficult to implement a slug test at the hinterland studied herein, relatively reliable specific yield could be feasibly obtained via a $\mathrm{pF}$ curve (a texture-based field capacity value). However, the specific yields obtained by this method are nondynamic and may also become a source of $\mathrm{ET}_{\mathrm{G}}$ estimation errors. Therefore, observations on the specific yield estimation in this study are further explained below.

Specific yields strongly depend on the DTWT in shallow groundwater environments and are dynamic in reality. Existing research [5] combined drainage experiments and simulation modeling methods to obtain the changes in specific yields with DTWT within 0 2 m. When DTWT was within $0.8 \mathrm{~m}$, specific yields varied as DTWTs became deeper. Then, there was a difference when depth is greater than $0.8 \mathrm{~m}$, and the effect of DTWT change on specific yields began decrease and approached a constant value that depended on soil texture. In another case, observations demonstrated that there was no significant correlation between specific yields and DTWT [51], for which the range of GWL changes was thought to be small and depth compensation in groundwater was not a key issue to consider. DTWTs varied from 0.8 to $1.1 \mathrm{~m}$ in the second case; therefore, to some extent, the results of the two studies mentioned above were consistent. In the present study of the Badain Jaran Desert, the DTWTs of each observation site was greater than $0.8 \mathrm{~m}$ (Figure 7) except the observation sites G3 and G5, which had DTWTs of less than $0.8 \mathrm{~m}$ during a short period of the beginning and end in the growing season. From this perspective, the changes in DTWTs at most observation sites had little effect on the specific yield estimations. Nevertheless, the specific yield estimation in this study was nondynamic as it did not account for the dynamic GWL temporal change rates relative to a pumping test estimation or the dynamic diurnal method. Therefore, the specific yield estimation may become a source of $\mathrm{ET}_{\mathrm{G}}$ estimation errors. According to Gribovzxki's comparison, the estimated specific yield in this study will be slightly higher than that calculated by the dynamic method. In future research, soil moisture monitoring instruments are expected to be added at groundwater observation sites to observe dynamic specific yields and thus improve $\mathrm{ET}_{\mathrm{G}}$ estimation accuracy.

\section{Conclusions}

Based on observed GWL and meteorological parameters in the lake basins of the Badain Jaran Desert, the characteristics of the regular diurnal GWL fluctuations in spatiotemporal scales and their relationship with vegetation were analyzed. Afterwards, the $\mathrm{ET}_{\mathrm{G}}$ was estimated via the White method, and the main controlling factors of $\mathrm{ET}_{\mathrm{G}}$ were explored. The observed series indicated that diurnal GWL fluctuations were consistent with the vegetation growing season, which was driven by groundwater consumption by phreatophytes. The amplitudes of diurnal GWL fluctuations showed marked differences among the sites, which was attributed to vegetation type and vitality. On a seasonal scale, the air temperature was an important external factor affecting the diurnal GWL fluctuations by controlling the vegetation phenology and groundwater consumption.

The estimated $\mathrm{ET}_{\mathrm{G}}$ was associated with vegetation type and exhibited a degree of association with the vegetation growth stage. The observation sites could be grouped into three categories based on the estimated results and vegetation type, and the $\mathrm{ET}_{\mathrm{G}}$ followed the general order Phragmites australis $>$ Achnatherum splendens $>$ Nitraria tangutorum. In the lake basins of the Badain Jaran Desert, the vegetation grew in the area where the DTWT was within $\sim 2 \mathrm{~m}$, and meteorological factors had a greater influence on vegetation transpiration than in other areas with higher DTWTs. Moreover, DTWT and PET are both important factors controlling the $\mathrm{ET}_{\mathrm{G}}$ rate, while their influence varied among observation sites.

This study further expands the geographical applicability of the White method and offers a new research paradigm for the study of diurnal GWL fluctuations in groundwaterdependent lakeside ecosystems. Additionally, the study results could become a scientific basis to solve the controversy on the formation mechanism of the lakes in the Badain Jaran Desert and support the sustainable usage of regional groundwater resources.

\section{Data Availability}

The groundwater level data and meteorological data used to support the findings of this study were supplied by the Center for Glacier and Desert Research, Lanzhou University, under license and so cannot be made freely available. Requests for access to these data should be made to the corresponding author.

\section{Conflicts of Interest}

The authors declare that they have no conflicts of interest.

\section{Acknowledgments}

We gratefully acknowledge the funding from the National Natural Science Foundation of China (41530745 and 41871021) and the Fundamental Research Funds for the Central University, Lanzhou University (lzujbky-2016-275). We thank Niu Zhenmin, Xu Xingbin, Liang Xiaoyan, and Wen Penghui from the Center for Glacier and Desert Research, Lanzhou University, for their contribution to the field work in this study. 


\section{References}

[1] F. Orellana, P. Verma, S. P. Loheide, and E. Daly, "Monitoring and modeling water-vegetation interactions in groundwaterdependent ecosystems," Reviews of Geophysics, vol. 50, no. 3, Article ID RG3003, 2012.

[2] E. Naumburg, R. Mata-gonzalez, R. G. Hunter, T. Mclendon, and D. W. Martin, "Phreatophytic vegetation and groundwater fluctuations: a review of current research and application of ecosystem response modeling with an emphasis on great basin vegetation," Environmental Management, vol. 35, no. 6, pp. 26-740, 2005.

[3] X. Li, L. Lu, G. Cheng, and H. Xiao, "Quantifying landscape structure of the Heihe River Basin, north-west China using FRAGSTATS," Journal of Arid Environments, vol. 48, no. 4, pp. 521-535, 2001.

[4] S. P. Loheide and S. M. Gorelick, "Riparian hydroecology: a coupled model of the observed interactions between groundwater flow and meadow vegetation patterning," Water Resources Research, vol. 43, no. 7, Article ID W07414, 2007.

[5] J. Fan, K. T. Ostergaard, A. Guyot, S. Fujiwara, and D. A. Lockington, "Estimating groundwater evapotranspiration by a subtropical pine plantation using diurnal water table fluctuations: implications from night-time water use," Journal of Hydrology, vol. 542, pp. 679-685, 2016.

[6] W. N. White, "A method of estimating ground-water supplies based on discharge by plants and evaporation from soil: results of investigations in Escalante Valley, Utah," USGS Numbered Series, Water Supply Paper 659-A, U.S. Government Printing Office, Washington, DC, USA, 1932.

[7] J. J. Butler, G. J. Kluitenberg, D. O. Whittemore et al., "A field investigation of phreatophyte-induced fluctuations in the water table," Water Resources Research, vol. 43, no. 2, Article ID W02404, 2007.

[8] J. Z. Drexler, R. L. Snyder, D. Spano, and K. T. Paw U, “A review of models and micrometeorological methods used to estimate wetland evapotranspiration," Hydrological Processes, vol. 18, no. 11, pp. 2071-2101, 2004.

[9] J. Zhu, M. Young, J. Healey, R. Jasoni, and J. Osterberg, "Interference of river level changes on riparian zone evapotranspiration estimates from diurnal groundwater level fluctuations," Journal of Hydrology, vol. 403, no. 3-4, pp. 381-389, 2011.

[10] L. Yin, Y. Zhou, S. Ge, D. Wen, E. Zhang, and J. Dong, "Comparison and modification of methods for estimating evapotranspiration using diurnal groundwater level fluctuations in arid and semiarid regions," Journal of Hydrology, vol. 496, pp. 9-16, 2013.

[11] P. Wang, S. O. Grinevsky, S. P. Pozdniakov et al., “Application of the water table fluctuation method for estimating evapotranspiration at two phreatophyte-dominated sites under hyper-arid environments," Journal of Hydrology, vol. 519, no. Part B, pp. 2289-2300, 2014.

[12] I. C. Reigner, "A method of estimating streamflow loss by evapotranspiration from the riparian zone," Forest Science, vol. 12, no. 2, pp. 130-139, 1966.

[13] P. Bauer, G. Thabeng, F. Stauffer, and W. Kinzelbach, "Estimation of the evapotranspiration rate from diurnal groundwater level fluctuations in the Okavango Delta, Botswana," Journal of Hydrology, vol. 288, no. 3-4, pp. 344-355, 2004.

[14] Z. Gribovszki, P. Kalicz, J. Szilágyi, and M. Kucsara, "Riparian zone evapotranspiration estimation from diurnal groundwater level fluctuations," Journal of Hydrology, vol. 349, no. 1-2, pp. 6-17, 2008.

[15] P. Wang and S. P. Pozdniakov, "A statistical approach to estimating evapotranspiration from diurnal groundwater level fluctuations," Water Resources Research, vol. 50, no. 3, pp. 2276-2292, 2014.

[16] C. E. Hughes, J. D. Kalma, P. Binning, G. R. Willgoose, and M. Vertzonis, "Estimating evapotranspiration for a temperate salt marsh, Newcastle, Australia," Hydrological Processes, vol. 15, no. 6, pp. 957-975, 2001.

[17] M. L. C. Mazur, M. J. Wiley, and D. A. Wilcox, "Estimating evapotranspiration and groundwater flow from water-table fluctuations for a general wetland scenario," Ecohydrology, vol. 7, no. 2, pp. 378-390, 2014.

[18] G. Yuan, Y. Luo, M. Shao, P. Zhang, and X. Zhu, "Evapotranspiration and its main controlling mechanism over the desert riparian forests in the lower Tarim River Basin," Science China Earth Sciences, vol. 58, no. 6, pp. 1032-1042, 2015.

[19] W. F. Yue, T. J. Wang, T. E. Franz, and X. H. Chen, "Spatiotemporal patterns of water table fluctuations and evapotranspiration induced by riparian vegetation in a semiarid area," Water Resources Research, vol. 52, no. 3, pp. 1948-1960, 2016.

[20] P. Wang, Y. Zhang, J. Yu, G. Fu, and F. Ao, "Vegetation dynamics induced by groundwater fluctuations in the lower Heihe River Basin, northwestern China," Journal of Plant Ecology, vol. 4, no. 1-2, pp. 77-90, 2011.

[21] V. Engel, E. G. Jobbágy, M. Stieglitz, M. Williams, and R. B. Jackson, "Hydrological consequences of Eucalyptus afforestation in the Argentine Pampas," Water Resources Research, vol. 41, no. 10, Article ID W10409, 2005.

[22] F. De Castro Ochoa and J. M. Reinoso, "Model of long-term water-table dynamics at doñana national park," Water Research, vol. 31, no. 10, pp. 2586-2596, 1997.

[23] L. K. Lautz, "Estimating groundwater evapotranspiration rates using diurnal water-table fluctuations in a semi-arid riparian zone," Hydrogeology Journal, vol. 16, no. 3, pp. 483-497, 2008.

[24] J. Fan, K. T. Oestergaard, A. Guyot, and D. A. Lockington, "Estimating groundwater recharge and evapotranspiration from water table fluctuations under three vegetation covers in a coastal sandy aquifer of subtropical Australia," Journal of Hydrology, vol. 519, no. Part A, pp. 1120-1129, 2014.

[25] J. F. Zhu, N. A. Wang, H. B. Chen, C. Y. Dong, and H. A. Zhang, "Study on the boundary and the area of Badain Jaran Desert based on remote sensing imagery," Progress in Geography, vol. 29, no. 9, pp. 1087-1094, 2010.

[26] N. Ma, N. A. Wang, Z. L. Li, X. L. Chen, J. F. Zhu, and C. Y. Dong, "Analysis on climate change in the northern and southern marginal zones of the Badain Jaran Desert during the period 1960-2009," Arid Zone Research, vol. 28, no. 2, pp. 242-250, 2011.

[27] N. A. Wang, N. Ma, H. B. Chen, X. L. Chen, C. Y. Dong, and Z. Y. Zhang, "A preliminary study of precipitation characteristics in the hinterland of Badain Jaran desert," Advances in Water Science, vol. 24, no. 2, pp. 153-160, 2013.

[28] N. Wang, K. Ning, Z. Li, Y. Wang, P. Jia, and L. Ma, "Holocene high lake-levels and pan-lake period on Badain Jaran Desert," Science China Earth Sciences, vol. 59, no. 8, pp. 1633-1641, 2016.

[29] X. S. Wang, X. N. Hu, X. M. Jin, L. Z. Hou, R. Y. Qian, and L. D. Wang, "Interactions between groundwater and lakes in Badain Jaran Desert," Earth Science Frontiers, vol. 21, no. 4, pp. 91-99, 2014. 
[30] Z. D. Zhu, Z. Wu, and S. Liu, An Introduction to Chinese Deserts, Science Press, Beijing, China, 1980.

[31] R. G. Allen, L. S. Pereira, D. Raes, and M. Smith, "Crop evapotranspiration: guidelines for computing crop water requirement," FAO Irrigation and Drainage Paper No. 56, pp. 1-15, Food and Agriculture Organization of the United Nations, Rome, Italy, 1980.

[32] S. P. Loheide, "A method for estimating subdaily evapotranspiration of shallow groundwater using diurnal water table fluctuations," Ecohydrology, vol. 1, no. 1, pp. 59-66, 2008.

[33] H. C. Troxell, "The diurnal fluctuation in the ground-water and flow of the santa ana river and its meaning," Transactions, American Geophysical Union, vol. 17, no. 2, pp. 496-504, 1936.

[34] R. W. Healy and P. G. Cook, "Using groundwater levels to estimate recharge," Hydrogeology Journal, vol. 10, no. 1, pp. 91-109, 2002.

[35] S. P. Loheide, J. J. Butler, and S. M. Gorelick, "Estimation of groundwater consumption by phreatophytes using diurnal water table fluctuations: a saturated-unsaturated flow assessment," Water Resources Research, vol. 41, no. 7, Article ID W07030, 2005.

[36] P. Meyboom, Bulletin 139-Groundwater Studies in the Assiniboine River Drainage Basin Part II: Hydrologic Characteristics of Phreatophytic Vegetation in South-Central Saskatchewan, Department of Energy, Mines and Resources Geological Survey of Canada, Canada, 1967.

[37] R. S. Crosbie, P. Binning, and J. D. Kalma, "A time series approach to inferring groundwater recharge using the water table fluctuation method," Water Resources Research, vol. 41, no. 1, Article ID W01008, 2005.

[38] A. R. Croft, "Water loss by stream surface evaporation and transpiration by riparian vegetation," Transactions, American Geophysical Union, vol. 29, no. 2, pp. 235-239, 1948.

[39] H. M. Tschinkel, "Short-term fluctuation in streamflow as related to evaporation and transpiration," Journal of Geophysical Research, vol. 68, no. 24, pp. 6459-6469, 1963.

[40] Z. Gribovszki, J. Szilágyi, and P. Kalicz, "Diurnal fluctuations in shallow groundwater levels and streamflow rates and their interpretation-a review," Journal of Hydrology, vol. 385, no. 1-4, pp. 371-383, 2010.

[41] P. Csáfordi, A. Szabó, K. Balog, Z. Gribovszki, A. Bidló, and T. Tóth, "Factors controlling the daily change in groundwater level during the growing season on the Great Hungarian Plain: a statistical approach," Environmental Earth Sciences, vol. 76, no. 20, p. 675, 2017.

[42] D.-H. Cheng, Y. Li, X. Chen, W.-K. Wang, G.-C. Hou, and C.-L. Wang, "Estimation of groundwater evaportranspiration using diurnal water table fluctuations in the Mu Us Desert, northern China," Journal of Hydrology, vol. 490, pp. 106-113, 2013.

[43] D. Cheng, J. Duan, K. Qian, L. Qi, H. Yang, and X. Chen, "Groundwater evapotranspiration under psammophilous vegetation covers in the Mu Us Sandy Land, northern China," Journal of Arid Land, vol. 9, no. 1, pp. 98-108, 2017.

[44] R. B. Jackson, J. Canadell, J. R. Ehleringer, H. A. Mooney, O. E. Sala, and E. D. Schulze, "A global analysis of root distributions for terrestrial biomes," Oecologia, vol. 108, no. 3, pp. 389-411, 1996.

[45] D. J. Cooper, J. S. Sanderson, D. I. Stannard, and D. P. Groeneveld, "Effects of long-term water table drawdown on evapotranspiration and vegetation in an arid region phreatophyte community," Journal of Hydrology, vol. 325, no. 1-4, pp. 21-34, 2006.
[46] M. A. Caird, J. H. Richards, and L. A. Donovan, "Nighttime stomatal conductance and transpiration in C3 and C4 plants," Plant Physiology, vol. 143, no. 1, pp. 4-10, 2007.

[47] P. W. Hare and R. E. Morse, "Water-level fluctuations due to barometric pressure changes in an isolated portion of an unconfined aquifer," Ground Water, vol. 35, no. 4, pp. 667$671,1997$.

[48] X. Sun, Y. Xiang, Z. Shi, X. Hu, and H. Zhang, "Sensitivity of the response of well-aquifer systems to different periodic loadings: a comparison of two wells in Huize, China," Journal of Hydrology, vol. 572, pp. 121-130, 2019.

[49] H. Zhang, Z. Shi, G. Wang, X. Sun, R. Yan, and C. Liu, "Large earthquake reshapes the groundwater flow system: insight from the water-level response to earth tides and atmospheric pressure in a deep well," Water Resources Research, vol. 55, no. 5, pp. 4207-4219, 2019.

[50] X.-W. Jiang, Z.-C. Sun, K.-Y. Zhao et al., “A method for simultaneous estimation of groundwater evapotranspiration and inflow rates in the discharge area using seasonal water table fluctuations," Journal of Hydrology, vol. 548, pp. 498507, 2017.

[51] Z. Gribovszki, "Comparison of specific-yield estimates for calculating evapotranspiration from diurnal groundwaterlevel fluctuations," Hydrogeology Journal, vol. 26, no. 3, pp. 869-880, 2018. 